\title{
Physical and Mechanical Properties of the Muds of the Fergoug Dam
}

\author{
A. Benaissa \\ Laboratory of Civil \\ Engineering and \\ Environment LGCE, \\ University of Djilali \\ Liabes de Sidi Bel \\ Abbes, Algeria \\ assia.benaiss@ \\ gmail.com
}

\author{
Z. Aloui \\ Laboratory of Civil \\ Engineering and \\ Environment LGCE, \\ University of Djilali \\ Liabes de Sidi Bel Abbes, \\ Algeria \\ labiodzh@ \\ yahoo.fr
}

\author{
M. S. Ghembaza \\ Laboratory of Civil \\ Engineering and \\ Environment LGCE, \\ University of Djilali \\ Liabes de Sidi Bel \\ Abbes, Algeria \\ ghembaza_moulay@ \\ yahoo.fr
}

\author{
H. Trouzine \\ Laboratory of Civil \\ Engineering and \\ Environment LGCE, \\ University of Djilali \\ Liabes de Sidi Bel \\ Abbes, Algeria \\ h_trouzine@ \\ yahoo.fr
}

\author{
Y. Sebaibi \\ Laboratory of Civil \\ Engineering and \\ Environment LGCE, \\ University of Djilali \\ Liabes de Sidi Bel \\ Abbes, Algeria \\ sebaibi2004@ \\ yahoo.fr
}

\begin{abstract}
Volumes of dredged sediments are rather considerable and are estimated approximately 600 million $\mathrm{m}^{3}$ per year worldwide. These can represent a very interesting source of raw materials, in particular for a sector consuming aggregates such as civil engineering. The work presented in this article is interested particularly in the valorization of the muds which come from the dam of Fergoug (Algeria), with an aim of improving their mechanical behavior using binders (cement, lime) in order to use them in road engineering. To this end, we carried out a series of physical, chemical, mechanical and mineralogical analyses presented in this paper.
\end{abstract}

Keywords- sediments of dredging; valorization; muds; road engineering; stoppings; mechanical behavior

\section{INTRODUCTION}

The recycling and re-use of waste in the field of construction has been an issue of increasing concern in the last years. In Algeria, the valorization of waste records a considerable delay, because of the absence of a policy favorable to the development of a waste market. Currently, several researchers direct their studies on the valorization of muds with an aim of using them in road engineering, an area calling for the greatest requirement out of materials. For the valorization of muds in this paper, the physicochemical characteristics initially measured (the limits of Atterberg, granulometry, the value with the methylene blue, the content of organic matter etc), are given according to French standards. The results obtained can be used to classify the studied sediments.

\section{MUD CHARACTERISTICS}

The sediments used in this study come from the Fergoug stopping which provides an illustration of the privileged surfaces of deposit of the eroded solid matters. Dam Fergoug is located at $20 \mathrm{~km}$ upstream of Perrégaux on the road of Mascara in Algeria (Figure 1a). It is an earth dam of initial capacity (in 1963) of 18 million $\mathrm{m}^{3}$. Its capacity fell to 17 million $\mathrm{m}^{3}$ in 4 years, and from 1970 to 1987 the rate of silting was $0.75 \mathrm{~m}^{3}$ per year [1]. Currently, the stopping "feeds" only the commune of Béthioua and its useful volume of storage reduced dramatically due to the sediment accumulation (Figure 1b).

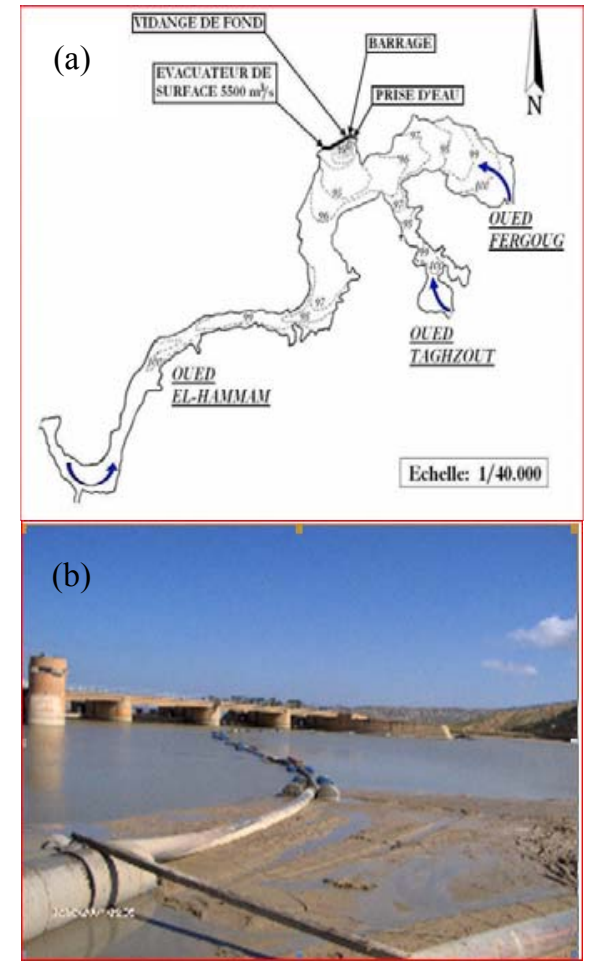

Fig. 1. (a) the restraint of Fergoug dam (b) Siltation at the level of the drain from the bottom of the dam

\section{A. Physical and geotechnical analysis}

The test sample selection in March 2007 was carried out manually using a shovel within ten meters of the right bank of 
the stopping. We determined the physical and geotechnical properties of this material. The parameters selected are those defined in [2] and are shown in Table I.

TABLE I. PHYSICAL AND GEOTECHNICAL CHARACTERISTICS OF THE BASE

\begin{tabular}{|c|c|c|c|c|c|c|}
\hline parameters & $\mathbf{W}_{\mathbf{L}} \mathbf{( \% )}$ & $\mathbf{W}_{\mathbf{P}} \mathbf{( \% )}$ & $\mathbf{I}_{\mathbf{P}}(\mathbf{\%})$ & $\gamma_{\mathbf{s}}\left(\mathbf{g} / \mathbf{c m}^{\mathbf{3}}\right)$ & $\mathbf{V}_{\mathbf{b}}$ & MO \%) \\
\hline Values (\%) & 34.28 & 17.79 & 16.49 & 2.50 & 5.50 & 4.40 \\
\hline
\end{tabular}

where: $\mathrm{W}_{\mathrm{L}}$ the liquid limit, $\mathrm{Wp}$ the plastic limit, $\mathrm{I}_{\mathrm{P}}$ the Index of plasticity, $\gamma_{\mathrm{s}}$ the voluminal weight of the solid matter constituents, $\mathrm{V}_{\mathrm{b}}$ the value of blue and MO the Organic Matter

\section{B. Chemical and mineralogical analysis}

The results of the analysis to the diffraction of x-rays made on the mud of Fergoug [1], give us an idea on principal crystalline minerals, by the existence of Quartz $\left(\mathrm{SiO}_{2}\right)$ with significant, followed peaks of carbonates (calcite $\left(\mathrm{CaCO}_{3}\right)$ and (dolomite), and a small quantity of Alumina $\left(\mathrm{Al}_{2} \mathrm{O}_{3}\right)$ represented in the form of Kaolinite $\left(\begin{array}{llll}\mathrm{Al}_{2} \mathrm{O}_{3} & 2 \mathrm{SiO}_{2} & 2 \mathrm{H}_{2} \mathrm{O}\end{array}\right)$. These resulted are confirmed by the chemical analysis, the results of which are shown in Table II.

TABLE II. CHEMICAL ANALYSIS RESULTS

\begin{tabular}{|c|c|c|}
\hline Characteristic & symbol & content \\
\hline Silica & $\mathrm{SiO}_{2}$ & 62.68 \\
\hline Lime & $\mathrm{CaO}$ & 12.51 \\
\hline Magnesia & $\mathrm{MgO}$ & 0.37 \\
\hline Alumina & $\mathrm{Al}_{2} \mathrm{O}_{3}$ & 7.39 \\
\hline Oxideof iron & $\mathrm{Fe}_{2} \mathrm{O}_{3}$ & 0.71 \\
\hline Sulphate & $\mathrm{SO}_{3}$ & 0.17 \\
\hline chloride & $\mathrm{CL}$ & 00 \\
\hline Loss in fire & $\mathrm{P.F}$ & 16.39 \\
\hline Total & & 100 \\
\hline Carbonate & $\mathrm{CaCO}_{3}$ & 22.73 \\
\hline Gas carbonic & $\mathrm{CO}_{2}$ & 10 \\
\hline Water combination & $\mathrm{H}_{2} \mathrm{O}$ & 6.39 \\
\hline
\end{tabular}

On the basis of the results of Table II, it is interesting to note that the principal mineralogical components of the mud are silica, followed by carbonates, then lime and finally alumina. Silica and alumina are minerals which constitute the structure of clays. The presence of calcium carbonate indicates that the mud belongs to the group of limestones clays. In addition, one notices that the loss on the ignition is rather significant, which proves the existence of organic matter in the mud.

\section{RESULTS INTERPRETATION}

The results of the geotechnical enables the classification of the material according to French criteria of road engineering, with a proportion of organic matter lower than $10 \%$. From the granulometry point of view, the materials are classified in heading of fine grained soils, noted class A. The subclass can be given according to the argillaceous activity $\left(\mathrm{V}_{\mathrm{b}}\right)$ and of the plastic character; however the parameters obtained can be contradictory. The value with blue and the limits of Atterberg make it possible to identify the mud under A2 class. The technical guide for the construction of the embankments and the subgrades indicated that if the index of plasticity $\left(I_{P}\right)$ is equal to or higher than 12 , it constitutes the identifying information adapted best. So the studied mud of the stopping of Fergoug is placed under class A2 [2].

\section{MECHANICAL STABILIZATION BY COMPACTION}

The geotechnical characteristics of our mud remain poor compared to officially accepted road materials. This provide a motivation to improve the mechanical properties of the muds by the addition of lime or cement CPJ 42,5. The Proctor test is carried out on the grounds obtained for various lime mud and cement mud mixtures with percentages $0,2,4,6$ and $8 \%$. The results are given by the curves of compaction with or without treatment in Figures 2 and 3.

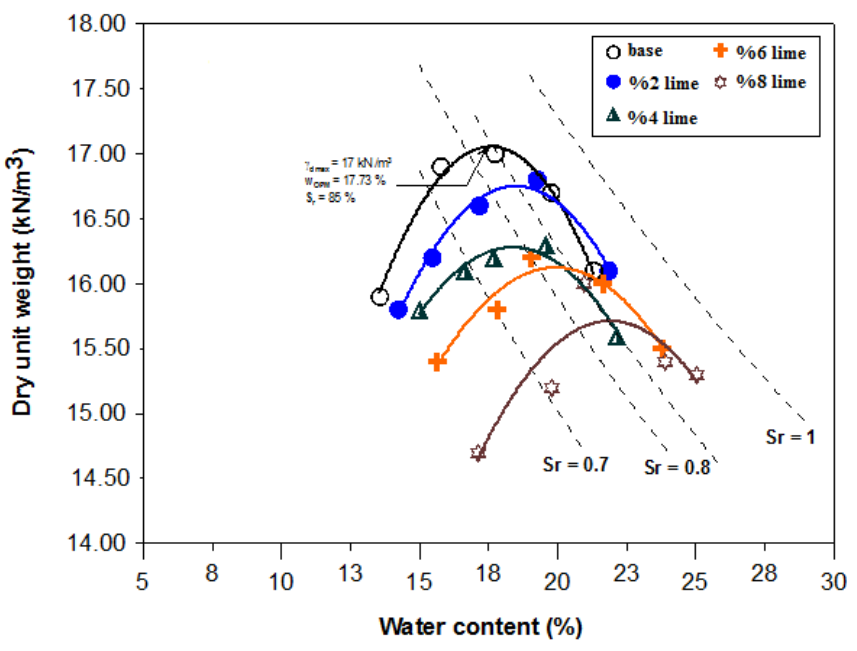

Fig. 2. Test Proctor of the base lime mixture

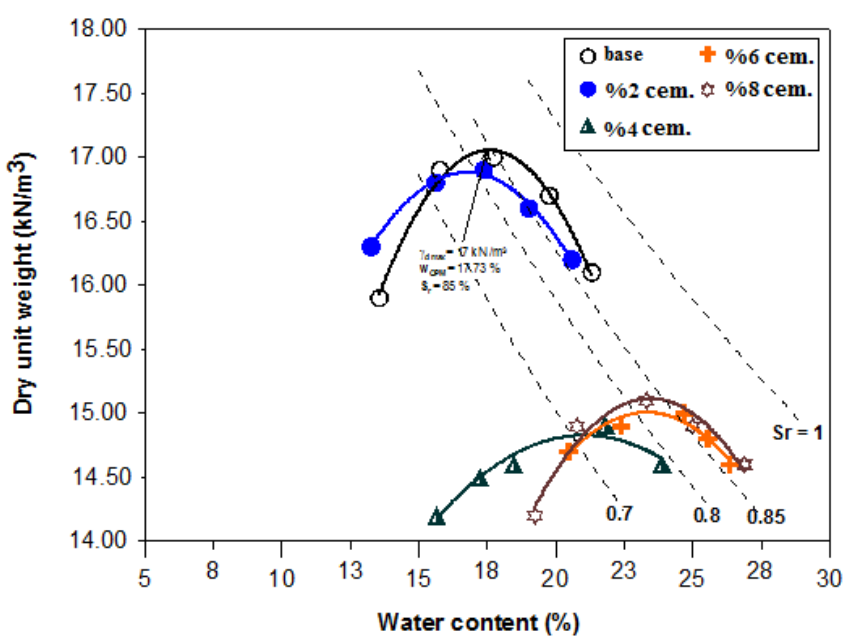

Fig. 3. Test Proctor of the base cement mixture 
From the results of the curves of the Proctor test, we noted that the untreated mud has a maximum dry density of 1.70 with a water content optimal located at approximately $17.73 \%$. After the treatment with lime or cement, one notes a displacement of the Proctor optimum towards a lower maximum dry density and a larger water content optimal. These results seem to be in agreement with those reported in [3] and [4].

\section{MECHANICAL BEHAVIOR-THE RECTILINEAR SHEAR TEST}

The shear tests were carried out with the Proctor optimum with various treatments of proportioning of lime and cement. The objective of this part is the determination of the strength to shearing parameters (the friction angle and cohesion). Another goal was to see the effect of the addition of the lime and cement chemical agents on the mechanical parameters. Results and related values are shown in Tables III and IV.

TABLE III. PARAMETERS OF THE SHEAR STRENGTH OF MIXTURES

\begin{tabular}{|c|c|c|c|c|c|}
\hline mix & $\begin{array}{c}+\mathbf{0 \%} \\
\text { lime }\end{array}$ & $\begin{array}{c}+\mathbf{+ 2 \%} \\
\text { lime }\end{array}$ & $\begin{array}{c}+\mathbf{+ 4 \%} \\
\text { lime }\end{array}$ & $\begin{array}{c}+\mathbf{6 \%} \\
\text { lime }\end{array}$ & $\begin{array}{c}+\mathbf{8 \%} \\
\text { lime }\end{array}$ \\
\hline $\mathbf{c}$ (KPa) & 145 & 154 & 171,67 & 214.33 & 203.33 \\
\hline $\boldsymbol{\phi}$ (degrees) & 22.05 & 34.21 & 36.87 & 35.18 & 30.33 \\
\hline
\end{tabular}

TABLE IV. PARAMETERS OF THE SHEAR STRENGTH OF MIXTURES

\begin{tabular}{|c|c|c|c|c|c|}
\hline mix & $\begin{array}{c}+\mathbf{0} \% \\
\text { cement }\end{array}$ & $\begin{array}{c}+\mathbf{+ 2} \% \\
\text { cement }\end{array}$ & $\begin{array}{c}+\mathbf{4} \% \\
\text { cement }\end{array}$ & $\begin{array}{c}+\mathbf{6 \%} \\
\text { cement }\end{array}$ & $\begin{array}{c}+\mathbf{8} \% \\
\text { cement }\end{array}$ \\
\hline $\mathbf{c}$ (KPa) & 145 & 221 & 93,33 & 156 & 132 \\
\hline $\boldsymbol{\phi}$ (degrees) & 22.05 & 27.70 & 29.03 & 8.53 & 28.37 \\
\hline
\end{tabular}

From the results of Tables III and IV, we represented graphically the variations of cohesion $\mathrm{C}$ and of the friction angle $\varphi$ according to the percentage of lime and cement (Figures 4-7).

\section{DISCUSSION}

We observe on Figure 4 that the measurements taken on the base-lime mixtures show an increase in cohesion according to the percentage of lime, with an optimum of the cohesion of 214 $\mathrm{Kpa}$ and $6 \%$ of lime. One notices the same observations for the natural friction angle (Figure 5), with an optimum of 29 degree for a percentage of 4\% lime. One can note in Figures 5 and 6 , that the values of cohesion and friction angle are not proportional to the added quantity of cement, thus the behavior of new material is influenced by the chemical reactions intern between various minerals. However, a quantity of cement of $2 \%$ clearly improves the cohesion $(221 \mathrm{Kpa})$ and the friction angle (27.7 degree).

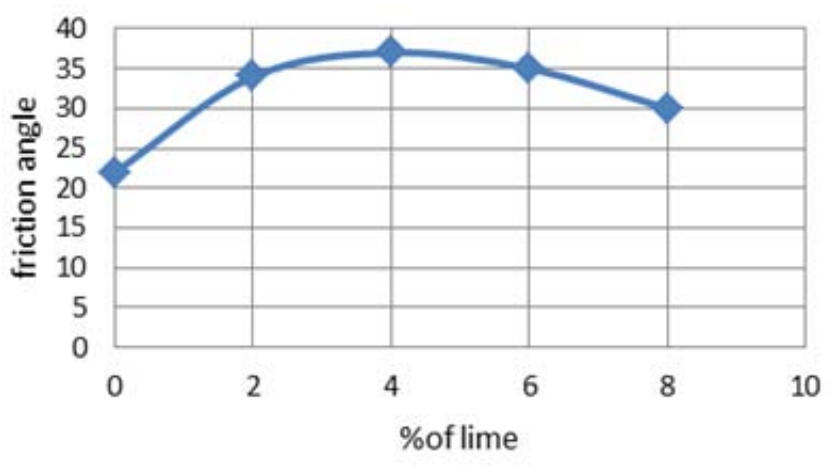

Fig. 4. cohesion vs the percentage of lime

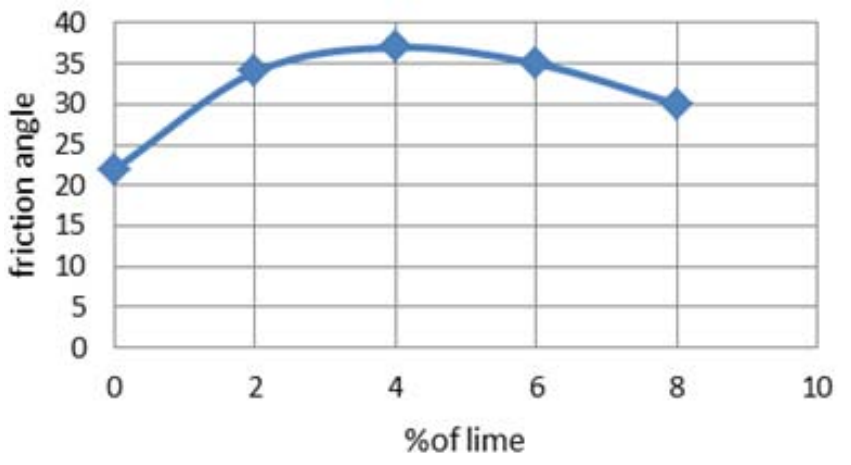

Fig. 5. friction angle vs the percentage of lime

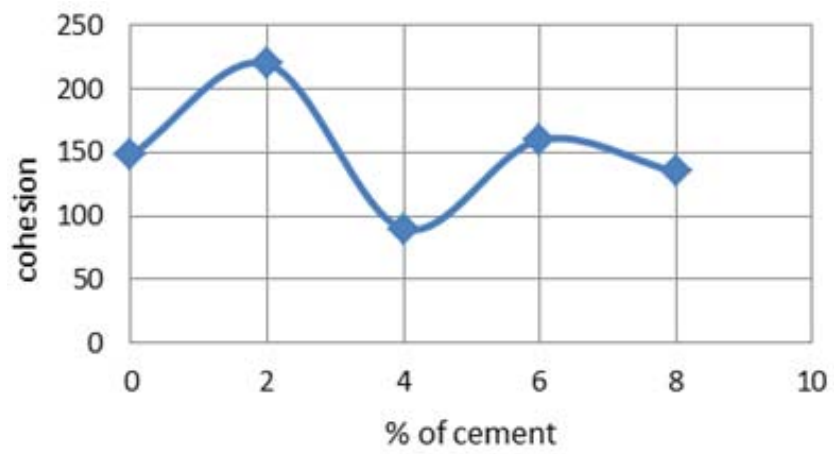

Fig. 6. cohesion vs the percentage of cement

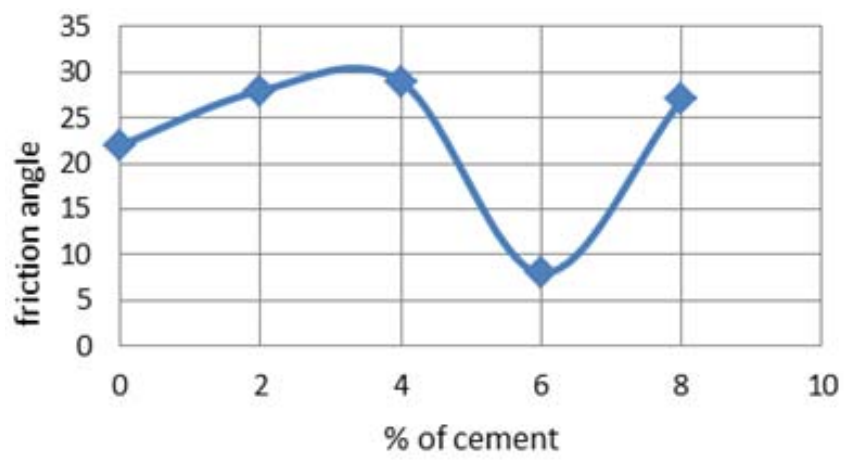

Fig. 7. friction angle vs the percentage of cement 


\section{CONCLUSION}

The treatment of the sediments with the hydraulic binders (lime and cement) showed clearly that several parameters of formulation influence the mechanical behavior, i.e. the hardening and the state of the treated mud. We notice that there are two kinds of parameters influencing the mechanical behavior of the treated mud; parameters related to the conditions of realization, like the water content, the malaxation and the energy of compaction; and the parameters which must remain in an extremely tight fork to lead to sufficient densities, in order to avoid the permanent deformations at the time of the implementation.

Other parameters influence the mechanical behavior directly, depending on the nature of the mud. The results of the shear tests show that some compounds can decrease the effectiveness of a treatment but without making the ground inapt for the treatment, such as the presence of organic matter in the ground (weak when expressed as a percentage, just $4.4 \%$ ). This, involves an embarrassment with respect to any addition and of any malaxation, they slow down the hydration of cement and trap the ions calcium and hydroxide which are responsible for the low mechanical resistances [3], as well as other elements like nitrate, sulphates, phosphate. One can also note that the nature and the proportioning of the treatment used will influence the mechanical behavior.

The mud treated with cement shows an anomaly in its behavior. The interpretation of the found values must be the analysis object of the structure (mud+cement). In any event, it is necessary to study the influence and the role of the organic matter present in the construction of structures. The organic compounds strongly interfere with the processes of hydrated or formation of the cementing phases. According to the results obtained, it is significant to note that the $5 \%$ lime treatment clearly improves the mechanical parameters of shearing. By comparing our results with those in [5], one notes that the mud treated with $5 \%$ lime presents a potential use of the material as a filling.

\section{REFERENCES}

[1] R. Boutin, Dragage et Rejets en Mer : Les Produits de Type Vase, Presses de l'Ecole Nationale des Ponts et Chaussées, Paris, 2000

[2] GTR, Technical Guide for the Realization of fill and of the subgrades, Booklet I, principles general, 1992

[3] M. Boutouil, Traitement of the muds of dredging by stabilisation/solidification containing cement and additive, $\mathrm{PhD}$ thesis, University of Le Havre, 1998

[4] N. Cant, Sols treated with lime and the binders hydraulics (contribution to the identification and the analysis disturbing elements of stabilization), PhD thesis, School of the Mines of Alés, 2004

[5] J. Bacot, A. Kham Khoeup, "Essais of stabilization muds estuariennes using hydraulic binders in sight of a use in road construction", INSA of Rennes, LGCGM-Equips Geology with the Engineer and with Environment, Department GCU, 2005 